\title{
Filling the gap between planning and doing: Psychological factors involved in the successful implementation of saving intention
}

\section{Abstract}

Previous research on the psychology of saving has tended to compare groups of savers and nonsavers without controlling for their intentions. As a result, the variables that are known to covary with saving/non-saving are mainly those that covary with forming saving intentions (attitudes, motives, etc.). However, the step from saving intention to actual saving is not straightforward and may require careful planning and efforts of self-control. In this respect it is important to know the factors that impact on the process of saving intention realisation. On the basis of insights from the behavioural life-cycle hypothesis [Shefrin, H. M. \& Thaler, R. H. (1992). Mental accounting, saving and self-control. In G. Lowenstein \& J. Elster (Eds.) Choice over time (pp. 287-330). New York: Russell Sage Foundation. $\lambda_{\lambda}$ and research on intention-behaviour consistency [Gollwitzer, P. M. (1993). Geal achievement: The role of intentions. In W. Stroebe \& M. Hewstone (Eds.) European Review of Social Psychology (Vol.4, pp. 141-186). Chichester, England: Wiley.), three factors are hypothesised to covary with successful implementation of saving intention: time horizon, usage of certain expenditure control techniques and perceived easiness of expenditure control. Two datasets are used in the study - a questionnaire survey conducted in Belarus in 2005 and several waves of the DNB Household Survey. In both datasets we compare two groups of respondents - those who planned to save and implemented this intention (the "plan-and-do" group) and those who planned to save, but failed to realise this plan (the "plan-in-vain" group). The data support the significance of time horizon and control techniques, while the 3rd factor - perceived easiness of expenditure control - receives mixed support. (C) 2006 Published by Elsevier B.V.

\footnotetext{
* Corresponding author. Tel.: +4407854852877.

E-mail address: a.rabinovich@ex.ac.uk (A. Rabinovich).
} 


\section{Introduction}

Saving rates in Europe and the USA have fallen dramatically since the 1970 s - early 1980s. An average American household today saves only about $0.5-1.0 \%$ of its disposable income, compared to about 11\% in 1984 (Ferguson, 2004). Similar trends are observed in Europe: for example, household saving rates in the UK have fallen to $5.9 \%$ in $2000-2002$ (compared to an average of $9.0 \%$ in 1990-1999), the percentage of household income saved in Italy has halved since the 1980s, whilst in 2002 saving rates in Finland were negative (Dirschmid \& Glatzer, 2004). An increase in the elderly population in developed countries and the inability of social security systems to provide an appropriate level of pension support brings the issue of personal saving to the front stage of contemporary social research.

Previous research in the field has established a range of psychological factors that covary with saving behaviour (see Nyhus, 2002; Wärneryd, 1999, for extended overviews). However, these findings have two limitations. First, all research has been conducted in developed countries with capitalistic economies. The variability of saving behaviour and its covariates appears to be much larger when we account for data from other regions with different economies (Rabinovich \& Webley, 2004). Recently there has been a significant interest in data from other economic and cultural environments in order to test the applicability of findings in different settings (for example, Schrooten \& Stephan, 2003). Thus, it would be desirable to test whether results obtained on capitalistic samples can be generalised to non-capitalistic environments. Second, previous research has tended to compare groups of savers and non-savers without controlling for their intentions. Differences in saving motives and intentions have been studied separately (Canova, Manganelli Rattazzi, \& Webley, 2005), and motives linked to saving behaviour (Nyhus \& Webley, 2001), but intention realisation issues have been overlooked in the empirical attempts to predict actual saving (see Daniel, 1997). It was assumed that as long as one intends to save the necessary action will be performed. However, saving may represent a complicated task that requires careful planning and efforts of selfcontrol (Thaler \& Shefrin, 1981). In this respect it is important to know (in terms of both theory and application) the factors that impact on the process of saving intention realisation.

This paper aims to compensate for these limitations. First, attention is focused on the intention realisation process. Two groups of respondents are compared: those who plan to save and carry out their plans ("plan-and-do" group), and those who are unable to realise their saving intentions ("plan-in-vain" group). A longitudinal approach is used in the Dutch dataset in order to distinguish these groups. Second, along with some data from the Netherlands, the study provides evidence from a transition economy (Belarus). The data from two countries are used in order to test the generalisability of findings for different economic settings. 
Contemporary studies of factors that influence consistency between intentions and actual behaviour fall into one of three types. Within the first, persistence in achieving a goal is attributed to the inner characteristics of goal intention itself, such as its strength, and binding to the goal is regarded as a consequence of these characteristics (Heckhausen $\&$ Kuhl, 1985). The second seeks reasons for (in)consistency in the goal realisation process in the cognitive domain, exploring anticipations of goal achievement or characteristics of decision making process. Within this framework self-efficacy, outcome expectations and affect towards action have been found to determine successful goal pursuit in the case of behaviours aimed at weight regulation (Bagozzi \& Edwards, 2000). Among decision characteristics, decision effort investment, importance and confidence in a decision were shown to be related to the likelihood of buying intention being realised (Dholakia \& Bagozzi, 2003). The third type of research links the success of intention maintenance and realisation to self-regulatory practices reinforcing it, such as forming an "implementation intention". This term, introduced by Gollwitzer (1993), refers to the intention to perform certain kinds of goal directed activity when the opportunity arises. Implementation intentions were shown to enhance the likelihood of goal directed behaviour over and above the influence of goal intention. This effect is achieved by bringing the opportunity for action within the scope of attention of the potential actor and linking goal directed behaviour to a clear situational cue, in other words, by partially automatising it. Using a wide range of behaviours, Gollwitzer and Brandstätter (1997) clearly showed that development of an implementation intention helps to overcome distractions and reach a goal.

Consistency between saving intention and behaviour has not been studied in detail before; the only factor involved in saving intention realisation that has received considerable theoretical attention is self-control, a concept that has been discussed in relation to saving for more than a century. According to Vohs and Baumeister $(2004$, p. 3$)$ the term "self-control" (used interchangeably with the term "self-regulation") refers to "any efforts by the human self to alter any of its own inner states or responses". There is an established tradition in psychology of measuring self-control as a stable personality trait. Recently, this trait has been shown to be related to a range of outcomes, such as school grades and interpersonal success (Tangney, Baumeister, \& Boone, 2004). Böhm-Bawerk (1890) and Fisher (1930) linked successful saving to individual differences in degree of impatience (or thrift) that influenced subjective utility of future goods. In its turn, the degree of impatience was dependent on a number of economic and socio-economic characteristics (such as age and social class) and a number of personal characteristics, far-sightedness and strong will (or self-control) among them.

Fisher (1930) proposed that self-control can be trained in the early stages of life. It is also true that certain techniques can be applied in order to enhance self-regulation when needed. Elster (1977) was the first to review and summarise techniques that allow us to compensate for weak self-control. Among these are pre-commitment (binding oneself in advance so that future impulses do not prevail), avoidance of risky environments, and imposing general rules, such as avoiding debt. These early ideas stress that saving is difficult due to self-control problems and that making saving unavoidable through pre-commitment and other techniques is important for its successful realisation.

These ideas were elaborated by Thaler and Shefrin in their "economic theory of selfcontrol" (1981) and later incorporated into the behavioural life-cycle hypothesis (Shefrin \& Thaler, 1988, 1992). Shefrin and Thaler described self-control difficulties associated with saving in terms of a conflict between a "planner" and a "doer" - two selves with different 
120 time horizons and consequently different optimisation strategies. The concept of two selves

121 incorporates both self-control and time horizon issues: due to differences in time horizon 122 the "planner" uses self-control resources in order to suppress actions guided by the "doer" 123 with a short time horizon. Thaler and Shefrin also provide a rational explanation for the 124 use of self-imposed rules such as living within one's means and avoiding borrowing. They 125 state that decreasing consumption at any given period requires self-control effort which is 126 psychologically costly (although they assume that this effort is always possible and it is 127 only a matter of cost). In order to avoid paying this cost, people engage in pre-commit128 ment that helps to save self-control energy. Automatic regular transfer of part of one's 129 income into a pension account is a good example of a cost-free pre-commitment that facil130 itates saving, as this procedure means that a decision needs only to be made once and thus 131 is costless in terms of self-control. Other rules include avoiding spending assets and a ban 132 on spending future income. These rules are closely related to the authors' idea of different 133 propensities to spend from different mental accounts. In order to be useful, rules of thrift134 iness should be simple, have only rare exceptions and be incorporated in habits. Shefrin 135 and Thaler provide numerous examples of their theory being supported by empirical facts 136 (for example, the existence of Christmas clubs and evidence that people enrolled in pension 137 plans at their workplace save more, as their saving is psychologically cost-free).

138 A new approach to saving and self-control was recently introduced by Baumeister and 139 Vohs (2003), who explored the nature of the self-regulation function in relation to inter140 temporal decisions. They describe self-control in terms of a power or energy resource 141 which is limited, can be used for multiple different tasks (ranging from physical activity to highly responsible decision making) and is managed frugally by human beings.

In spite of the theoretical importance attached to the problem of saving intention realisation, there is hardly any empirical research. Some empirical investigations of self-control and saving were carried out by Daniel (1997), but the results were inconclusive. Recently, the self-control concept was studied in relation to impulse buying (Faber \& Vohs, 2004). This investigation is highly relevant to saving as it is acknowledged that in their efforts to save people undertake actions to control their consumption (Wärneryd, 1999). Faber and Vohs understand self-control as a limited resource. They assume that intensive usage of self-control for one task reduces our ability to exercise it equally successfully in other tasks. Faber and Vohs experimentally depleted subjects' self-control resources and then faced them with the tempting possibility of buying goods with discounts. They found out that those whose self-control was depleted tended to spend more on impulse.

Due to the dataset considerations, in this study we do not deal with the global construct of self-control, but with selected parameters that give us broader insight into relationship of self-control and saving. Relevant dataset considerations and hypotheses are discussed in the next section.

\section{Dataset considerations and hypotheses}

The Dutch dataset was not designed specifically for the purposes of this study. While the DNB Household Survey offers the advantages of large representative samples and longitudinal measurement, it provides a limited range of psychological variables to use. There is no direct measure of self-control in the Dutch dataset. However, the dataset includes 
164

165

several measures that are related to the need for self-control in saving. The variables measured and their relevance to self-control are briefly described below.

\subsection{Time horizon}

Time horizon refers to the length of time period that is taken into account in the process of planning expenditures and savings. It has been shown to be one of the most robust covariates of saving behaviour in previous research (Nyhus, 2002; Wärneryd, 1999): it helps to discriminate between savers and non-savers and to predict saving behaviour. Time horizon is linked to the need for self-control in saving by the behavioural life-cycle hypothesis (Shefrin \& Thaler, 1988). According to the two selves model, those whose "planner" dominates over the "doer" have a longer time horizon and are more likely to exercise selfcontrol successfully in order to suppress responses initiated by the "doer". Thus, both time horizon and active use of self-control are linked to the dominance of the "planner" who is initiating saving behaviour. This serves the basis for our first hypothesis.

Hypothesis 1. The plan-and-do group has a longer time horizon than the plan-in-vain group.

\subsection{Expenditure control techniques}

The idea that the use of certain techniques may enhance self-control resources and increase the likelihood of saving was introduced by Elster (1977). One of the key techniques described by him was pre-commitment: arrangements that provide a defense against future impulses. The concepts of expenditure control techniques usage and selfcontrol are linked through the two theoretical perspectives: mental accounting (Shefrin \& Thaler, 1992) and implementation intention (Gollwitzer \& Brandstätter, 1997). According to the mental accounting framework, certain techniques such as transferring money to a separate account (or transferring it into a different currency) facilitate labeling this money as a separate source distinct from other income. Different mental accounts have a different propensity to spend, thus money labeled as "savings" through transfer to a different form are less likely to be spent. Consequently, when savings are transferred to a specific mental account, less self-control resources are required to refrain from spending it (i.e. the propensity to spend is lower).

According to the implementation intention framework, goal attainment is facilitated through formation of specific context-related plans. The effect is achieved due to linking the desired behaviour to a specific situational trigger. For example, a person may decide to floss their teeth after brushing them in the evening. In this case, "brushing teeth" would be the trigger for the planned action. The planned action would happen partially automatically and would require less will-power. In this respect, the use of certain expenditure control techniques that link saving to certain actions, events or time periods could facilitate saving through influencing the amount of self-control resource necessary for action initiation. For example, a decision to set aside a certain sum of money on the day salary is received facilitates saving through making it an automatic consequence of the expected event (receiving salary). This arrangement should be even more effective if the transfer is done through a direct debit. These considerations form the basis of our second hypothesis. 
Hypothesis 2. The plan-and-do group uses techniques that make saving automatic and complicate spending savings more often than the plan-in-vain group. These techniques include the automatic transfer of part of income into a saving account or (in Belarus) the transfer of savings into a foreign currency.

\subsection{Perceived easiness of expenditure control}

Perceived easiness of expenditure control is related to the concept of perceived behavioural control in the Theory of Planned Behaviour (Ajzen, 1985). We suggest that perceived behavioural control is not always adequate in the case of saving (which is permitted by planned behaviour theory) and thus other factors of actual behavioural control may interfere (e.g. techniques usage). The significance of perceived easiness of expenditure control for saving was first demonstrated by Wärneryd (1998) and then replicated by Webley, Burlando, and Viner (2000). In both studies this variable was included in the optimal models for predicting saving. This variable is currently widely accepted as a predictor of saving behaviour (see also Nyhus, 2002). We hypothesise that it is also related to successful saving intention implementation, which has not been tested before.

The relationship between perceived easiness of expenditure control and self-control is twofold. First, perceived easiness of expenditure control is related to the general amount of self-control resource available and can be used as a proxy measure for self-control. On the other hand, perceived easiness is related to self-efficacy and reflects the perceived difficulty of a saving task and the perceived likelihood of achieving a saving goal. In this respect, this measure reflects a perceived balance between a saving task's demand on self-control resources and the actual availability of these resources. Thus, people who have either strong self-control or perceive saving as an easy task in relation to self-control resources available are more likely to have sufficient resources to realise their saving intention. Hence, our third hypothesis.

Hypothesis 3. The plan-and-do group will perceive expenditure control as an easier task in comparison to the plan-in-vain group.

For all three hypotheses we intend to generalise the findings to non-capitalistic economic setting. Thus, we test our hypotheses on two samples: capitalistic western economy (Dutch sample) and non-capitalistic transition economy (Belarus).

\section{Method and sample}

The results from two datasets are presented here: a secondary analysis of the DNB Household Survey that uses a large panel of Dutch respondents and a face-to-face questionnaire survey conducted in Belarus.

\subsection{Participants}

Dutch. Data were collected from a representative sample of the Dutch population with computer-assisted methods. The sampling procedure used telephone directories as the sampling frame. Respondents whose numbers were selected were contacted by phone and invited to take part in the research in return for the use of a PC and modem. About 
$24418 \%$ of households that were originally contacted agreed to participate. As some groups

245 (such as single persons and older households) were less likely to agree, quotas for certain

246 social parameters were introduced. Details of sample forming and data collection proce247 dures can be found in Nyhus (1996).

248 The DNB Household Survey is conducted annually. Due to the drop-out rate, which is quite significant (see Table 1), the panel is regularly refreshed with new participants. 251 agreement between saving plans and saving behaviour stayed the same for at least two

252 subsequent years. This was done in order to select respondents with stable behavioural 253 patterns.

254 Respondents in the first group planned to save and saved for two years subsequently. 255 For example, people who planned in 2002 to put money aside next year and then saved in 256 2003, and planned in 2003 to put money aside and saved in 2004 were in this group. It was 257 named the "plan-and-do" group. The second group included respondents who planned to 258 save, but did not save during two subsequent years. In 2002 they reported their intention 259 to save the next year and then did not save in 2003, and again in 2003 they planned to save 260 in the following year, yet did not save in 2004. This group was called the "plan-in-vain" 261 group. Respondents in the third group repeatedly did not plan to save and did not in fact 262 save. This was labelled the "saving rejection" group. Finally, the last group comprised 263 respondents who did not plan to save, but somehow managed to save for two years sub264 sequently. Only the first two groups are used in the following analysis. In order to distinguish the groups, data from three subsequent waves of survey (2002-2004) were used.

The same procedure of distinguishing four groups was repeated for the years 2000-2002 and 1998-2000. Thus, we analysed three sets of two groups: the first set is made up of people who behaved consistently in years 2002-2004, the second of those who did so in 20002002 and the third of those who demonstrated the same patterns of behaviour over the years 1998-2000. These are different sets of people, as the percentage who drop-out is very high (see Table 1) and the panel of respondents is replaced almost completely in four years. Bearing in mind that although the drop-out rate is high, it may be the case that newcomers drop-out more frequently than "core" participants who stay in the panel for years, and thus an overlap between datasets may emerge, we carefully checked for cases appearing in more than one dataset (this was possible as each case has a unique number). No cases appeared in two datasets. The group sizes and their weight in the general sample are given in Table 2.

The 2002-2004 sample consisted of 821 respondents, of whom 54.7\% were male and $45.1 \%$ were female. Ages ranged from 23 to 91 (mean 51). Fifty-four percent were

Table 1

Rates of drop-out in DNB household survey

\begin{tabular}{lll}
\hline Year & Frequency of drop-out & Percent of drop-out \\
\hline 2004 & 502 & 24.28 \\
2003 & 697 & 29.56 \\
2002 & 908 & 34.10 \\
2001 & 567 & 29.32 \\
2000 & 615 & 45.29 \\
1999 & 515 & 37.73 \\
\hline
\end{tabular}


Table 2

Split of total samples into groups with consistent behaviour

\begin{tabular}{|c|c|c|c|c|c|c|c|c|}
\hline \multirow[t]{2}{*}{ Group } & \multicolumn{2}{|l|}{ 2002-2004 } & \multicolumn{2}{|l|}{ 2000-2002 } & \multicolumn{2}{|l|}{ 1998-2000 } & \multicolumn{2}{|l|}{ Belarus } \\
\hline & Frequency & Percent & Frequency & Percent & Frequency & Percent & Frequency & Percent \\
\hline Plan-and-do & 706 & 86.0 & 424 & 87.6 & 230 & 81.3 & 104 & 37.0 \\
\hline Plan-in-vain & 49 & 6.0 & 24 & 5.0 & 16 & 5.7 & 49 & 17.5 \\
\hline Saving rejection & 63 & 7.7 & 34 & 7.0 & 37 & 13.1 & 111 & 39.5 \\
\hline Unplanned saving & 3 & 0.4 & 2 & 0.4 & 0 & 0 & 17 & 6.0 \\
\hline Total & 821 & 100 & 484 & 100 & 283 & 100 & 281 & 100 \\
\hline
\end{tabular}

employees, $2.7 \%$ - self-employed, $0.9 \%$ - students and $18.9 \%$ - retired. The $2000-2002$ sample consisted of 484 respondents, of whom $57.2 \%$ were male and $42.8 \%$ female. Ages ranged from 23 to 85 (mean 51). Fifty-four percent were employees, $1.2 \%$ - self-employed, $1.2 \%$ - students and $20.9 \%$ - retired. The 1998-2000 sample consisted of 283 participants, of whom $62.5 \%$ were male and $37.1 \%$ were female. Ages ranged from 29 to 81 (mean 56). Forty percent were employed and $15.6 \%$ - retired (other information on occupation categories is not available).

Although the size of groups varies significantly over the years (due to the fact that the drop-out rate has somewhat decreased in recent years and general sample size increased), the percentage of respondents falling in each of the planning/saving group is very consistent. The plan-and-do group is the biggest - more than $80 \%$ of respondents plan to save and are able to realise their plans in two subsequent years. Other groups are significantly smaller. The plan-in-vain group comprises about $5-6 \%$ of the population and people who do not intend to save represent about $8 \%$. Thus there is a small but consistent group of respondents who are not able to carry out their saving intentions.

Belarusian. The second data set was collected through a face-to-face questionnaire survey in Minsk, the capital city of Belarus, in May 2005. The sample is representative for the city population by gender, age group and city district. Inside the specified cells respondents were chosen pseudo-randomly. There were 283 respondents ( $54 \%$ female), aged between 20 and 79 (average age 39.6). The monthly reported individual income ranged from 800 to $3,000,000$ Belarusian roubles, with average income of 448,000 roubles (about 225 US dollars), which corresponds well to the average income level in the city. Forty-two percent of respondents saved during the last year.

Respondents were allocated to the same four groups - plan-and-do, plan-in-vain, saving rejection and unexpected saving - as the Dutch sample. The only difference was that saving plans in the Belarusian sample were measured retrospectively: respondents were asked to recollect whether they planned to save a year ago, whilst in the Dutch sample answers from the previous year's questionnaire were used.

\subsection{Questionnaires}

Dutch. Members of the panel completed five long questionnaires each year. In this paper only the data from the "Economic and Psychological Concepts" questionnaire are used. Full details of the questionnaires can be obtained from the DNB Household Survey website (http://www.uvt.nl/centerdata/dhs/). The items included in the analysis are described in the "variables measurement" section below. 
Belarusian. The questionnaire consisted of nine parts and 50 questions. It included questions on saving socialisation, money management and temptation coping strategies, saving behaviour and motives, usage of bank services, attitudes to money and socio-economic and demographic indicators.

\subsection{Variables measurement}

Time horizon. The question about time horizon was the same in both questionnaires: "People use different time horizons when they decide about what part of the income to spend and what part to save. Which of the time horizons mentioned below is in your household most important in regard to expenditures and savings?" (In the Belarusian questionnaire the question asked "Which of the time periods is most important for you..."). The answer options were different in the two questionnaires. For the Dutch sample they ranged from "next couple of months" to "more than 10 years from now". For the Belarusian sample they ranged from "next month or less" to "next 5-10 years". The answer options for Belarus were different because we knew from previous studies that the time horizon for economic decisions in Belarus is very short (see Rabinovich \& Webley, 2004), so it was necessary to include the shorter option. There were five ordinal answer options in both questionnaires. In the Dutch sample the cross-wave correlations for timehorizon were not very high $(2003 / 2004 r=0.42 ; 2001 / 2002 r=0.43 ; 1999 / 2000 r=0.42)$. In the Dutch sample all independent variables were measured in the first year of each twoyear period (for example, if a respondent demonstrated the same behaviour in 2003 and 2004, the independent variables were measured in 2003). This was based on the assumption that parameters measured during the planning year would have more impact on implementation behaviour; the parameters measured when the plan is already implemented or failed are of less significance for prediction of success or failure. In the Belarusian sample saving behaviour and independent variables were measured at one point of time.

Expenditure control techniques. In the Dutch questionnaire nine expenditure control techniques were listed. They included keeping a house-keeping book, not having credit cards or cheques, securing tax return, having a limited amount of money on oneself, withdrawing only a certain amount from the bank at the beginning of each month, transferring a certain amount to a saving account automatically each month, returning things bought on impulse back to shops, avoiding shopping and doing something else to control expenditures. For each technique respondents had to answer whether they used it or not. The kappa values (coefficients of inter-wave agreement) were not high for most techniques: for automatic transfer to a separate account, $0.42-0.55$; for avoiding shopping, $0.37-$ 0.39 ; for taking things back to shops, 0.32-0.45; for keeping a house-keeping book,

1-0.62; for not having a credit card or cheques, 0.16-0.40; for securing tax return, $3510.28-0.40$; for having little money on oneself, $0.35-0.38$; for withdrawing a fixed amount, $0.38-0.41$.

In the Belarusian questionnaire respondents were asked whether they used the following expenditure control techniques: not keeping much money on oneself, avoiding going shopping, planning budget in advance, keeping money for different purposes separately, keeping a house-keeping book, persuading oneself that one does not need things that are tempting, putting part of income separately and trying to forget about it, transferring part of income into a separate bank account, transferring part of income into a foreign 
359

360

361

currency, transferring foreign currency back to national currency by small amounts. Some of the techniques were the same as for the Dutch sample, while others were specific for Belarus.

For the purposes of the analysis some of the techniques were combined into a "minor shopping-related techniques" scale. This included three highly correlated techniques in the Dutch sample (avoiding shopping, having limited money on oneself and returning things to shops) and two of these techniques in the Belarusian sample (avoiding shopping and having little money on oneself; returning things back was not measured in the Belarusian survey). If a respondent used at least one of these techniques, she scored 1 on the scale, if she did not use any of them, she scored 0.

Perceived easiness of expenditure control. This was measured with one question which was the same in both questionnaires: "How difficult is it for you to control your expenditures?" with answers on a 7-point scale ranging from "very easy" to "very difficult". For the Dutch sample the cross-wave correlations for this item were 0.57 (2004/2003), 0.54 (2002/2001) and $0.21(2000 / 1999)$.

Saving plans and saving. In the Dutch questionnaire respondents were asked "Are you planning to put money aside in the next 12 months?" They had four ordinal answer options from "yes, certainly" to "certainly not". For the purpose of analysis the first two options ("yes, certainly" and "yes, perhaps") were combined together, and the same was done with the two last options ("probably not" and "certainly not"). There was also a "don't know" option. The answers to this question were compared with the answers of the same respondents to the question "Did you put any money aside in the last 12 months?" in the following year's questionnaire.

In the Belarusian questionnaire saving plans were measured retrospectively. Respondents were asked the following question: "A year ago, did you plan to save during this year?" They had to answer "yes" or "no". Later in the questionnaire they were asked whether they had saved during the last 12 months, with possible answers being "yes" or "no". Thus, in both questionnaires saving was measured by self-report measures.

\section{Results}

Outliers on income were removed in both datasets before the analysis.

\subsection{Differences in time horizon}

Table 3 contains the results of pairwise comparisons between the plan-and-do and planin-vain groups in Belarus and in three two-year periods in the Netherlands.

In all four datasets differences in time horizon between the plan-and-do and plan-invain groups are statistically significant (see Table 3), with successful savers planning their finances further ahead. At the same time estimates of effect size vary from year to year. The effect size is very pronounced in the 1998-2000 period in the Dutch data, is moderate in Belarusian sample, but is fairly small in the latest two periods of the Dutch data. However, the data consistently show that people who successfully implement their saving plans have longer time horizons in comparison with those who fail to realise their plans. Thus, Hypothesis 1 is supported by the data.

As it may be argued that the result obtained is due to a positive relationship between time horizon and income, we also present data for those respondents whose income lies 
Table 3

Differences in time horizon

\begin{tabular}{|c|c|c|c|c|c|c|}
\hline Variable & & $\mathrm{N}$ & Mean & $t$ & $p$ & $\begin{array}{l}\text { Cohen's } \\
d\end{array}$ \\
\hline Netherlands 2002-2004 & $\begin{array}{l}\text { Savers } \\
\text { Non- } \\
\text { savers }\end{array}$ & $\begin{array}{r}692 \\
47\end{array}$ & $\begin{array}{l}2.32 \\
1.83\end{array}$ & 2.76 & .006 & 0.20 \\
\hline Netherlands 2000-2002 & $\begin{array}{l}\text { Savers } \\
\text { Non- } \\
\text { savers }\end{array}$ & $\begin{array}{r}424 \\
24\end{array}$ & $\begin{array}{l}2.34 \\
1.67\end{array}$ & 3.82 & .001 & 0.25 \\
\hline Netherlands 1998-2000 & $\begin{array}{l}\text { Savers } \\
\text { Non- } \\
\text { savers }\end{array}$ & $\begin{array}{r}230 \\
16\end{array}$ & $\begin{array}{l}2.42 \\
1.38\end{array}$ & 5.297 & $<.001$ & 2.26 \\
\hline Belarus & $\begin{array}{l}\text { Savers } \\
\text { Non- } \\
\text { savers }\end{array}$ & $\begin{array}{r}104 \\
49\end{array}$ & $\begin{array}{l}2.03 \\
1.71\end{array}$ & 1.92 & .057 & 0.33 \\
\hline $\begin{array}{l}\text { Netherlands 2002-2004, income between 40th and 60th } \\
\text { percentiles }\end{array}$ & $\begin{array}{l}\text { Savers } \\
\text { Non- } \\
\text { savers }\end{array}$ & $\begin{array}{r}529 \\
38\end{array}$ & $\begin{array}{l}2.31 \\
1.76\end{array}$ & 3.02 & .003 & 0.23 \\
\hline Belarus, income between 40 th and 60 th percentiles & $\begin{array}{l}\text { Savers } \\
\text { Non- } \\
\text { savers }\end{array}$ & $\begin{array}{l}89 \\
38\end{array}$ & $\begin{array}{l}2.00 \\
1.71\end{array}$ & 1.65 & .100 & 0.36 \\
\hline
\end{tabular}

between 40 th and 60 th percentiles, representing $20 \%$ of the sample with income level closest to average. The results are still statistically significant for the Netherlands. Although for the Belarusian sample the results are significant at the level of $p=0.1$, the means of time horizon length for two groups are the same as in the analysis for the whole sample and the effect size of the difference is even bigger. ${ }^{1}$ This shows that lower estimate of statistical significance of the difference is rather due to decreased number of observations in this case. Thus, we conclude that the relationship between time horizon and saving plan implementation exists independently of income level.

Table 4 provides evidence that the relationship between the length of time horizon and successful saving is linear - the longer ahead people plan, the more likely it is that they will implement their saving plans. For example, in the Belarusian sample $26.8 \%$ of respondents who plan their finances for a month or less implement saving plans successfully, but the percentage of successful savers increases up to $72.7 \%$ among those who plan for couple of years ahead.

We have also controlled for age in this analysis. Entering age as a covariate in the GLM analysis with time horizon as a dependent variable and type of saver as a predictor, we found that after controlling for age the difference in time horizon between successful and unsuccessful savers is still significant $(F=2.5, p=0.09)$.

\footnotetext{
${ }^{1}$ We have also controlled for the influence of income by conducting a GLM univariate analysis with time horizon as a dependent variable, type of saver (plan-and-do vs. plan-in-vain) as a predictor and income as a covariate. The analysis showed that after controlling for income the difference in length of time horizon between two groups of savers is still significant $(F=5.01, p=0.002)$.
} 
Table 4

Percent of successful savers in groups with different time horizon

\begin{tabular}{llllll}
\hline Length of time horizon & \multicolumn{2}{c}{ Netherlands 2000-2002 } & & \multicolumn{2}{c}{ Belarus } \\
\cline { 2 - 3 } & $N$ & Percent & & 38 & Percent \\
\hline Month or less & - & - & 80.9 & 37 & 26.8 \\
Couple of months & 144 & 89.9 & 19 & 39.4 \\
Year & 89 & 90.8 & 8 & 59.4 \\
Couple of years & 118 & 92.3 & 2 & 100 \\
5-10 years & 48 & 100 & - & - \\
More than 10 years & 25 & &
\end{tabular}

\subsection{Differences in usage of expenditure control techniques}

421 The data in Table 5 show that successful Dutch savers are often involved in contractual 422 saving, transferring part of their income automatically into a different bank account. This 423 should make saving psychologically easier, as it makes day-to-day efforts to save unnecessary. On the other hand, respondents who are not able to realise their saving intentions use minor shopping-related techniques: they try to avoid shopping, keep little money on themselves or return bought goods. Techniques used more by the "plan-in-vain" group are often less "technical", simpler and require effort each day to carry them out.

The data for Belarus are different. The differences in the use of separate bank accounts between the two groups are insignificant and the percentage of respondents who use separate accounts for saving is much lower. The reason is that opening a bank account in Belarus is a rather complicated procedure. It requires a certain amount of income which means that not everyone who wants to use this technique for expenditure control is able to do so. Consequently, people use other techniques that are more available - for example, they transfer their savings into foreign currency. We believe that this behaviour fulfils the same functions as transferring money into a separate account in the Netherlands: it keeps it separate and makes spending it more complicated. In addition, a transfer into foreign currency is a precaution against inflation. The data in Table 5 show that Belarusian respondents who transfer their savings into foreign currency are more likely to implement their saving plans successfully.

We also controlled for the influence of income level in these findings. The users of separate accounts are better-off in comparison with non-users in Belarus, which is expected and determined by banks' policy. But users and non-users of the technique of transferring into a foreign currency do not differ in income level. The differences in income between the Dutch users and non-users of separate accounts are also statistically insignificant. Thus, the relationship between the use of expenditure control techniques and the realisation of saving plans exists independently of income. Hypothesis 2 is thus supported by the data.

\subsection{Differences in easiness of expenditure control}

The data on differences in perceived easiness of expenditure control are not conclusive (see Table 6). The differences between the plan-in-vain and plan-and-do groups are statistically insignificant in the Belarusian sample and in 1998-2000 period of the Dutch data. But differences for the 2000-2002 and 2002-2004 periods of the Dutch panel are significant 


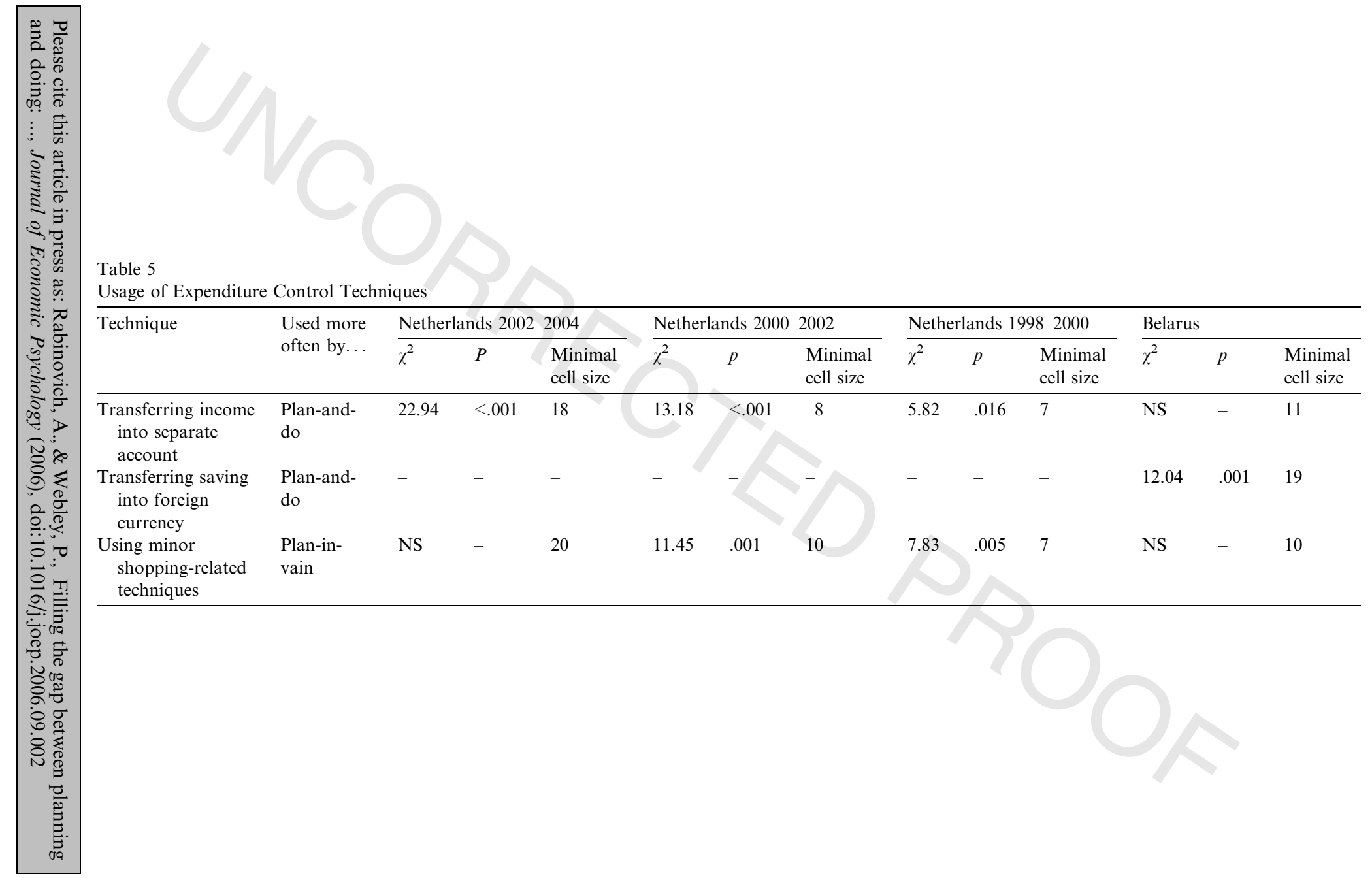


Table 6

Differences in perceived easiness of expenditure control

\begin{tabular}{|c|c|c|c|c|c|c|}
\hline Variable & & $N$ & Mean & $t$ & $p$ & Cohen's $d$ \\
\hline \multirow[t]{2}{*}{ Netherlands 2002-2004 } & Savers & 685 & 2.79 & 4.52 & $<0.001$ & 0.34 \\
\hline & Non-savers & 45 & 3.76 & & & \\
\hline \multirow[t]{2}{*}{ Netherlands 2000-2002 } & Savers & 424 & 2.77 & 1.84 & 0.067 & 0.17 \\
\hline & Non-savers & 24 & 3.38 & & & \\
\hline \multirow[t]{2}{*}{ Netherlands 1998-2000 } & Savers & 230 & 2.45 & NS & - & - \\
\hline & Non-savers & 16 & 3.00 & & & \\
\hline \multirow[t]{2}{*}{ Belarus } & Savers & 104 & 3.12 & NS & - & - \\
\hline & Non-savers & 49 & 3.39 & & & \\
\hline
\end{tabular}

and have quite big effect sizes. Thus, the data do not fully support Hypothesis 3, but do not allow us to reject it either.

\section{Discussion}

We hypothesised that three factors covary with successful implementation of saving intention - time horizon, usage of expenditure control techniques and easiness of expenditure control.

Time horizon has been one of the most robust covariates of saving behaviour in previous research (Nyhus, 2002; Wärneryd, 1999): it helps to discriminate between savers and non-savers and predict saving behaviour. This study shows that its influence is robust to having an intention to save - the differences in time horizon still exist when only respondents with saving intention are included in the analysis. This means that the impact of time horizon is not limited to forming saving intentions. Not only do people who think ahead understand the importance of saving more and are more inclined to make saving plans, but they also carry out their plans more successfully. An explanation of the link between time horizon and ability to realise saving plans through income differences does not hold as the effect sizes of differences in length of time horizon between groups do not change when controlling for income. Although income level correlates significantly with both ability to save and length of planning period (especially in Belarus), there is a covariation between ability to save and time horizon independent of income. This relationship is also likely to be robust to cultural differences. In this study we obtained very similar results for two societies with very different historical and cultural backgrounds as well as different economic conditions. Although the averages of planning period were very different in two cultures (with a mode of a month or less in Belarus and a year in the Netherlands), the significant differences in time horizon between plan-and-do and plan-in-vain groups were found in both samples. Moreover, the relationship between time horizon and successful saving plans implementation is likely to be linear.

Construal level theory (Liberman \& Trope, 2004) links the notions of time perspective and preferences in a way that can shed some light on the relationship between successful saving and planning period. It states that if an event is at a far temporal distance it is evaluated from the perspective of its central attributes, while when we consider closer events, peripheral attributes become more important. If we assume that saving is a central goal for people who intend to save, then, according to this theory, it should be the focus of attention of people with a long time horizon. They would also be more likely to concentrate on 
485

486

487

488

489

490

491

492

493

494

495

496

497

498

499

500

501

502

503

504

505

506

507

508

509

510

511

512

513

514

515

516

517

518

519

520

521

522

523

524

525

526

527

528

529

530

531

the central attributes of this goal, such as the final purpose of saving. People with a short time horizon will be prone to concentrate on more peripheral aspects such as the restriction of immediate consumption needs and this lessens their chance of realising saving plans.

It is also possible that a shorter time horizon makes people underestimate future expenditures. These people are less likely to take into account long-term factors such as the growth of children's needs or inflation rates, they generally think about the future in less detail and this makes their plans less elaborate and flexible, which is the reason for their more frequent failure. This hypothesis needs further investigation.

The importance of expenditure control techniques that emerged in this study stresses the issue of self-control in relation to saving and reinforces the view that similar psychological processes underlie saving and other behaviours requiring self-control (such as dieting). The techniques that covary with successful implementation of saving plans have one thing in common: they make the saving process partially automatic and require less reliance on will-power (unlike other strategies that are more often used by plan-in-vain group, such as avoiding shopping, having little money on oneself and returning things to shops). The successful expenditure control techniques may result from "implementation intentions": sets of simple rules that link a desired behaviour to clear situational clues (such as "as soon as I get my salary, I will transfer $20 \%$ of it to a separate account"). These findings are in line with previous research showing that forming an implementation intention increases the chances of successful plan realisation (Gollwitzer \& Brandstätter, 1997).

The results on the use of expenditure control techniques are also in line with research on problematic debt by Webley and Nyhus (2001) who found that more "high-tech" and long-term techniques such as automatic bank transfer are more often used by people without debts, while debtors more often avoid shopping and return things to shops.

The mental accounting perspective is another framework that is relevant to the results on the usage of expenditure control techniques. Keeping money in a separate account or in a separate currency not only complicates spending it physically, but also fosters a different psychological perception of this money. As soon as money is transformed to a different form or account, it is incorporated into the "assets" mental account which is less likely to be spent.

The notions of self-control, mental accounting and time horizon are all linked to saving in the behavioural life-cycle theory (Thaler \& Shefrin, 1992). The assumptions of this theory are largely supported by the data. The fact that successful and unsuccessful savers differ in the length of time horizon is in line with the two selves model. In terms of the behavioural life-cycle hypothesis, having a long time horizon means being under the control of the "planner" who ensures that saving plans are carried out. Differences in the usage of expenditure control techniques relate to the behavioural life-cycle hypothesis in two ways. First, the automatic transfer to a separate account is a typical example of a self-imposed rule that reduces the psychological cost of restricting consumption by avoiding frequent decision making. Second, useful techniques activate the usage of other rules - such as a ban on spending assets - through transferring saved income into a different mental account. Thus, the data provide some support for two concepts of the behavioural life-cycle hypothesis the two selves model and the mental accounting framework.

The results for perceived easiness of expenditure control may be inconclusive for two reasons. We suggested that people who perceive expenditure control as an easier task either need less energy to cope with it or have more self-control resources initially and thus have 
higher chances of exercising expenditure control successfully. But although expenditure control may be perceived as an equally easy task by two people, they may have different other demands for their self-control resource and thus have different amount of self-control to deal with an expenditure control task. Although we measured the construct that reflects perceived easiness of the task and initial amount of will-power available to achieve it, we did not control for other demands for will power in the respondents' environment. The other possible reason is the imperfection of measurement - easiness of expenditure control was measured with only one item and did not account for individual differences in general self-control.

This study does have some limitations. First, the intensity of intention to save was not controlled for, although it might have a significant impact on intention-behaviour consistency (see for example Gollwitzer, 2006). ${ }^{2}$ Second, the degree of intention implementation was not measured. The participants were not asked how much they planned to save, so it was not possible to measure whether they completely realised their plan (i.e. planned to save $€ 100$ and saved $€ 100$ ) or less (for example, saved $€ 50$ whilst they planned to save $€ 100)$. Thus, the respondents were classified as successful savers if they reported any savings, even if this was a smaller sum than the one they intended to save. These limitations were imposed by the Dutch data. It would be desirable to control for intensity of intention and degree of plans realisation in future research.

Another limitation of the study is related to the small cell sizes in the analysis of expenditure control techniques usage. Both the number of unsuccessful savers and the number of users of some techniques were rather small in the earlier waves of the Dutch data. However, wherever this problem occurs, the results in question are supported (by statistically significant results or by the tendency) by the results from other waves, which do not suffer from the small cell size problem.

It is also necessary to note that the focus of this paper is on individual saving. However, the saving decisions of individuals who are members of households are influenced by other household members. This problem is beyond the scope of this paper, but represents a promising direction for future research (see for example Meier, Kirchler, \& Hubert, 1999).

Finally, the reliability of the findings is slightly compromised by the differences in measurement of saving intention in the two samples. The retrospective measure of saving plans (used in the Belarusian sample) may be biased, as the result of the saving attempt is already known by the time of reporting. However, in spite of this problem, the results of the analysis are very consistent with the Dutch sample findings, where a longitudinal approach was used. This consistency, in spite of differences in measurement, lends even more support to the conclusions.

The results of this study have implications for further research. First, the relationship between self-control and saving should be explored in more detail. Especially beneficial would be any attempts to establish causal links. For example, currently available data do not allow us to state that there is a causal link between the usage of certain expenditure

\footnotetext{
${ }^{2}$ The Dutch data provided a measure of commitment to saving plans ("Are you planning to put money aside in the next 12 months?" with four ordinal answer options from "certainly yes" to "certainly not") that could be interpreted as a measure of intensity of intention. Our preliminary analysis showed that the percentage of those who implemented their intention did increase with the increase of intention intensity as measured by the above indicator. However, for the purposes of the study this measure was recoded into two options (having or not having intention to save) (see Section 3).
} 
control techniques and successful realisation of saving plans, although the fact of the relationship between two variables has strong factual support. Proceeding from the regulatory resource model (Baumeister \& Vohs, 2003), we can also suggest that there should be a link between depletion of self-control energy and failure to implement saving plans. Testing this hypothesis requires an experimental approach.

If there is a relationship between self-control and successful saving, it is important to know what other factors can interfere with this. Physical exhaustion and stress are hypothesised to decrease one's ability to exercise self-control (Baumeister \& Heatherton, 1996), and thus these variables may be related to the implementation of saving intention. This possibility may have considerable social significance, as it means that low saving rates among lower social classes may be associated not only with lower income, but also with higher levels of general stress.

This paper has looked at saving behaviour from a new perspective, investigating the factors that interfere with the process of saving intention realisation and compensating for the previous lack of attention to the step from planning saving to implementation of those plans. It has shown that several psychological and behavioural factors, such as time horizon and usage of expenditure control techniques are reliably related to success in realisation of saving plans.

\section{Acknowledgement}

The authors are grateful to CentERdata institute for their kind permission to use the DNB Household Survey data.

\section{References}

Ajzen, I. (1985). From intentions to actions: A theory of planned behavior. In J. Kuhl \& J. Beckman (Eds.), Action-control: From cognition to behavior (pp. 11-39). Heidelberg: Springer.

Bagozzi, R. B., \& Edwards, E. A. (2000). Goal striving and implementation of goal intentions in the regulation of body weight. Psychology and Health, 15, 255-270.

Baumeister, R. F., \& Heatherton, T. F. (1996). Self-regulation failure: An overview. Psychological Inquiry, 7, $1-15$.

Baumeister, R. F., \& Vohs, K. D. (2003). Willpower, choice and self-control. In G. Lowenstein, D. Read, \& R. Baumeister (Eds.), Time and decision economic and psychological perspectives on intertemporal choice (pp. 201-215). NY: Russell Sage Foundation.

Böhm-Bawerk, E. von. (1890). Capital and interest [George D. Huncke, Hans F. Sennholz, Trans.]. South Holland, Ill.: Libertarian Press. (Original work published 1959).

Canova, L., Manganelli Rattazzi, A. M., \& Webley, P. (2005). The hierarchical structure of saving motives. Journal of Economic Psychology, 26, 21-34.

Daniel, T. R. (1997). The economic psychology of saving. Ph.D. thesis, Exeter, UK.

Dholakia, U. M., \& Bagozzi, R. P. (2003). As time goes by: How goal and implementation intentions influence enactment of short-fuse behaviours. Journal of Applied Social Psychology, 33, 889-922.

Dirschmid, W. \& Glatzer, E. (2004). Determinants of the household saving rate in Austria. Monetary policy and the Economy, Q4/04, 25-38. Retrieved at <www.oenb.at/en/img/mop_2004_4_analyses2_tcm16-23739.pdf > 2.08.2005.

Elster, J. (1977). Ulysses and the sirens: A theory of imperfect rationality. Social Science Information, 16, 469-526.

Faber, R., \& Vohs, K. D. (2004). To buy or not to buy? self-control and self-regulatory failure in purchase behavior. In R. F. Baumeister \& K. D. Vohs (Eds.), Handbook of self-regulation: Research, theory and application (pp. 509-524). NY: Guilford Press.

Ferguson, R. W. (2004). Questions and reflections on the personal saving rate. Remarks to the National Bankers Association, Nashville, Tennessee, 6 October 2004. 
Fisher, I. (1930). The theory of interest. London: Macmillan.

Gollwitzer, P. M. (1993). Goal achievement: The role of intentions. In W. Stroebe \& M. Hewstone (Eds.). European Review of Social Psychology (Vol. 4, pp. 141-186). Chichester, England: Wiley.

Gollwitzer, P. M. (2006). Open questions in implementation intention research. Social Psychological Review, 8 , $14-20$.

Gollwitzer, P. M., \& Brandstätter, V. (1997). Implementation intentions and effective goal pursuit. Journal of Personality and Social Psychology, 73, 186-199.

Heckhausen, H., \& Kuhl, J. (1985). From wishes to action: The dead ends and short cuts on the long way to action. In M. Frese \& J. Sabini (Eds.), Goal-directed behavior: The concept of action in psychology (pp. 134-160). Hillsdale, NJ: Erlbaum.

Liberman, N., \& Trope, Y. (2004). Construal level theory of intertemporal judgement and decision. In G. Lowenstein, D. Read, \& R. Baumeister (Eds.), Time and decision. Economic and Psychological perspectives on intertemporal choice (pp. 245-275). NY: Russel Sage Foundation.

Meier, K., Kirchler, E., \& Hubert, A. C. (1999). Savings and investment decisions within private households: Spouses' dominance in decisions on various forms of investment. Journal of Economic Psychology, 20, 499-519.

Nyhus, E. K. (1996). The VSB-Center savings project: Data collection methods, questionnaires and sampling procedures. Progress Report no. 42. VSB-CentER savings project. Tilburg: CentER, Tilburg University.

Nyhus, E. K. (2002). Psychological determinants of household saving behaviour. Bergen, Norges Handelsheskole.

Nyhus, E. K., \& Webley, P. (2001). The role of personality in household saving and borrowing behaviour. European Journal of Personality, 15, 85-103.

Rabinovich, A. \& Webley, P. (2004). Individual differences and predictors of saving behaviour in a transition economy. In B. Yang Lester (Ed.), Cross-fertilization between economics and psychology. Proceedings on CDrom of the SABE/IAREP 2004 Conference Philadelphia, LeBow.

Schrooten, M. \& Stephan, S. (2003). Private Savings in Eastern European EU-Accession Countries: Evidence from a Dynamic Panel Data Model. German Institute for economic research, Discussion paper 372. Berlin.

Shefrin, H. M., \& Thaler, R. H. (1988). The behavioral life-cycle hypothesis. Economic Inquiry, 26, 609-643.

Shefrin, H. M., \& Thaler, R. H. (1992). Mental accounting, saving and self-control. In G. Lowenstein \& J. Elster (Eds.), Choice over time (pp. 287-330). New York: Russell Sage Foundation.

Tangney, J. P., Baumeister, R. F., \& Boone, A. L. (2004). High self-control predicts good adjustment, less pathology, better grades and interpersonal success. Journal of Personality, 72, 271-322.

Thaler, R. H., \& Shefrin, H. M. (1981). An economic theory of self-control. The Journal of Political Economy, 89, 392-406.

Vohs, K. D., \& Baumeister, R. F. (2004). Understanding self-regulation: An introduction. In R. F. Baumeister \& K. D. Vohs (Eds.). Handbook of self-regulation: Research, theory and application (pp. 1-12). NY: Guilford Press.

Wärneryd, K.-E. (1998). Personality, future-orientation, self-control and saving. Paper presented at the TMR Savings Workshop, CentER, Tilburg.

Wärneryd, K.-E. (1999). The psychology of saving: A study on economic psychology. Cheltenham: Edward Elgar.

Webley, P., Burlando, R.M., \& Viner, A. (2000). Individual differences, savings motives and saving behaviour: A cross national study. In E. Hölzl (Ed.), Fairness and cooperation: IAREP/SABE conference proceedings (pp. 497-501). Vienna: WUV.

Webley, P., \& Nyhus, E. K. (2001). Life-cycle and dispositional routes into problem debt. British Journal of Psychology, 92, 423-446. 